International Journal of Language, Literature and Gender Studies (LALIGENS), Ethiopia

Vol. 5 (1), Serial No 11, February, 2016:67-81

ISSN: 2225-8604(Print) ISSN 2227-5460 (Online)

DOI: http://dx.doi.org/10.4314/laligens.v5i1.6

\title{
The Dynamics of Voice Qualifiers in Discourse: Adichie's Purple Hibiscus
}

\author{
Akujobi, O. S. \\ Department of English Language/Literature \\ Nnamdi Azikiwe University, Awka \\ Anambra State, Nigeria \\ E-mail:odochiakujobi@yahoo.com
}

\begin{abstract}
Voice qualifiers play complementary roles to speech in the comprehension of messages in a discourse. They elicit various emotions, attitudes and dispositions of the speaker in a communicative environment. Voice qualifiers are the most understudied elements of human discourse. Humans can phonate on and off, and can equally raise or lower their pitches. By the sound of the voice we can differentiate when somebody is happy, threatened or frightened. Humans can consciously control their discourse by their voluntary laryngeal control. Purple Hibiscus is replete with voice qualifiers, which helped in creating clearer meanings in the text and showcased the decisive need of voice qualifiers in discourse. For effective communication, it is imperative that conversationalists understand and master these key interactive techniques. The study investigates some of the workings of voice qualifiers such as pitch, rate and tone in discourse using Adichie's Purple Hibiscus as a model; based on Poyatos concept of voice qualifiers and Ferdinand de Saussure's Semiotic Theory. The study showed that paralinguistic voice qualifiers influence discourse by using qualifiers like: 'Eh?', 'Oh?' and 'gbo'. These indicated emotional questioning, which deepens the meanings of questions that are being asked, to indicate that the sender of the message demands an answer. Tremulous voice indicated nervousness and being overwhelmed by emotion.
\end{abstract}


Whispery voice indicated secrecy. It is therefore recommended inter alia that language users should learn to adopt the right use of voice qualifiers, to reduce ambiguity in discourse.

Key words: Voice qualifiers, Discourse, Adichie's Purple Hibiscus

\section{Introduction}

The human voice is a unique tool that is specific to everyone and like a fingerprint, it is an identifier. The voice has varied qualities that make each voice distinct. They are tone, rate and pitch etc. According to Reiman "A change in pitch is known as inflection and humans exercise this naturally all the time. People tend to exercise conscious control of the pitch of their voice when refraining from screaming, because it tightens and strains the vocal cord..." (Web).The voice is usually expressed by sounds made while whispering, giggling, talking, singing, laughing, crying etc. Smiling and crying are innate non-verbal actions. The voice can be modulated to be creaky, husky, and nasal etc, to create whichever effect that is desired. Horror films are made using creaky voices to create a chilly effect. Some advertisements are made with low breathy voices to create a charming effect. Babies are usually cooed with lip rounding. When people are angry or excited, their speech becomes higher and faster. It slows down when they are bored or feeling down and is abrupt when they are feeling defensive. Anxiety can be observed in ones vocal behavior. A speech can be said to be eloquent when there are reduced unfilled pauses like Ah!, Oh!, Eh!, Aaaaah! Etc. These are at times caused by tension, emotional instability or stress. There are equally other vocal behaviors that can lead to speech disturbances. Example: Stammering, omission, tongue slip etc. The voice can be used to control the direction of speech air according to Poyatos

While the direction of speech air is almost always egressive, the use of ingressive air is possible, first of all, in linguistic reflex-like verbal utterances of surprise, expectancy or fear..., emotional questioning....the 'Yeah' and 'No', as a repeated affirmation or negation. Para linguistically, ingressive air is used to utter, for instance, a reflex hiss when physically hurt, a contemptuous sniff, a single-pulse laugh or a fearful gasp...spasmodic laughter; the duration must be differentiated between fast, as in a gasp or a panic-stricken 'Help!', and prolonged or slow, as in a long, anguished 'Aaaaah'.(182)

The personality of a person can most often be visible through the power of the voice. Dominance can equally be observed through the voice. The use of voice qualifiers in discourse in any communicative environment cannot be overemphasized. The right use of voice qualifiers in discourse and in the right communicative environment leads to clearer comprehension of vocal messages. Discourse is seen as the type of language used in a particular context. Everyone is subject to the power of discourse. Discourse 
is defined by Dijk (qtd in Weiss and Wodak) from the point of Critical discourse analysis as "a communicative event including conversation interaction, written texts as well as associated gestures, face work, typographical layout, images and any other semiotic and multimedia dimensions of signification" (13). Paralanguage is a form of discourse that extends beyond mere words. One sentence can have varied meanings depending on the word you emphasized on in the sentence.

Paralinguistic devices are the major tools for the determination of the direction and purpose of every discourse especially ambiguous ones. It amply empowers conversationalists to observe the sincerity among one another. According to Wikimedia, " $70 \%$ of the messages we communicate are through paralanguage...the meaning and interpretation of paralanguage is defined by ones culture" (Web) Leading scholars in this area of research include: David Crystal, Lyons John, Sebeok, T.A. Hayes, A.S., Bateson, M.C., Ray Birdwhistle etc. The absence of paralanguage in most communicative environments jeopardizes the clear comprehension of such communications and leads to avoidable conflicts.

The communicative procedures of human beings are very complicated. A higher percentage of human discussions are conveyed through paralanguage, which is also viewed as language. "Language has been described as a system of conventional signals used for communication by a whole community. This pattern of conventions covers a system of significant sound units, the inflection and arrangement of words and the association of meaning with words." (Gimson, 4).

Inflection is a form of paralanguage that are applied vocally to a message and such inflections can alter the meaning of the message. One can say 'good morning' but the tone says 'bad morning' and the recipient becomes offended. Paralanguage is the major ingredient used in every language to convey emotions and feelings through voice qualifiers etc. Hall posits that language is "the institution whereby humans communicate and Interact with each other by means of habitually used oral auditory arbitrary symbols." (158)

Any communication can only be said to be successful if the message is well understood by the recipient. Communication is defined by Wikipedia as

the activity of conveying information through the exchange of thoughts, messages, or information, as by speech, visuals, signals, writing or behaviour. It is the meaningful exchange of information between two or more living creatures (Web).

In most communicative processes, there must be feedback. There must be a sender of the message and the receiver of the message and the message must be well understood in the right perspective for communication to take place. Paralanguage when used in 
any discussion is more dependable than only verbal elements, due to the 'Tell Tale' signs that are unavoidably present during speech events.

\section{According to Davies and Widdowson:}

the actual phonetic realization of language elements is only one component of face-to face communication......and that this also includes such paralinguistic components as tone of voice and gesture. Paralinguistic features must be added to make more meaning (163164).

Paralinguistic devices are meant to complement vocal linguistic expressions. So all paralinguistic devices must according to Abercombie: "Communicate and be part of a conversational interaction" (164).

Paralinguistic devices are used in different forms to exchange information. Through their use one communicates a vast amount of feelings. People are able to tell if one is happy, sad, angry, nervous or scared just by listening to your voice, looking at your facial expression and your body movement. People tend to trust the paralinguistic cues more than the information content of their discussions. According to Davies and Widdowson:

The principal purpose of the paralinguistic elements in speaking is to express the speaker's attitude either to what he is saying or to whom he is saying it. Their function is essentially a modal one. (164)

The crucial need of paralanguage can also be viewed in the use of emoticons in writing mails to add context to what is being said as the facial expressions and tone of voice cannot be seen at the point of communication.

Paralinguistic devices are culture bound due to the fact that all human languages are equally culture bound. People of different ethnic groups are bound to misunderstand one another due to the inability of people to understand one another's paralinguistic behaviour. According to O'Neil:

These auxiliary communication techniques are highly culture bound. Communication with people from other societies or ethnic groups is fraught with the danger of misunderstanding, if their culture and paralanguage is unknown to you or ignored (Web).

Language is actually more than words, so we cannot underestimate the importance of paralinguistic devices in all types of interpersonal relationships. Voice qualifiers control the flow of conversation, emotional condition and impressions. 


\section{The Concept of Paralinguistic Qualifiers}

Poyatos' Concept of Paralinguistic Qualifiers: Poyatos' concept of Paralinguistic Qualifiers was classified into ten (10). Some of them are:

a) Breathing Control: Ingressive and Egressive Sounds: "While the direction of speech air is almost always egressive, the use of ingressive air is possible, first of all, in linguistic reflex-like verbal utterances of surprise, expectancy or fear..., emotional questioning....the 'Yeah' and 'No', as a repeated affirmation or negation. Paralinguistically, ingressive air is used to utter, for instance, a reflex hiss when physically hurt, a contemptuous sniff, a single-pulse laugh or a fearful gasp...spasmodic laughter; the duration must be differentiated between fast, as in a gasp or a panic-stricken 'Help!', and prolonged or slow, as in a long, anguished 'Aaaaah' ".(182) Ingressive sounds are sounds that are made when speech sounds are pronounced by inhaling, while egressive sounds are speech sounds that are pronounced by exhaling.

b) Laryngeal Control: The following voice types are identified as laryngeal control: Whispery voice, Breathy voice, Glottal stop and glottal catch, creaky voice, falsetto voice, harsh voice, strident voice and shrill voice qualities, squeaking, squealing, screeching, squawking, metallic voice, voice roughness, hoarse, tremulous or quavering voice, tense voice and lax voice.

"Squeaking, squealing, screeching, squawking. These four voice types are shrill voices. Squeaking, a high-pitched sound 'Squawking is also harsh, but abrupt, less piercing and not so long as squealing, as frightened hens sound" (Poyatos, 185).

c) Falsetto Voice. At the high end of the pitch scale, falsetto or 'light voice' associated with a young girl's innocence and with affectionate ways of addressing someone, is typical of Anglo-American in general-a little higherpitched and spreading over longer utterances among black Americans-to express surprise (e.g. what?!'), emphatic affirmation ('Yeah!', Black 'Yeah, man!'), several forms of laughter, etc.(poyatos 183). Examples of high varieties of falsetto are 'ventricular falsetto' ('Seal voice') and the one 'usually referred to as the 'flute', 'whistle' or 'pipe' register(...) exhibited by a few women and children' (Hollien, 1974, p.127)

d) 'Tremulous or quavering voice. The last voice quality caused by the form of vibration is tremulousness (Lat. tremulous, tremere, to tremble) or quavering (Lat. Quaveren, shaking of the voice), caused by muscular tremor which produces an irregular or pulsating quality, as when one is nervous or overwhelmed by emotion'(186) 
e) Whispered Voice: There are three main degrees of whispered speech in a scalar continuum: Soft whispered voice (Oversoft), usually used with a mouth-to-ear posture for utmost secrecy; normal whispered voice ... producing normal voice (e.g. in a theatre) and forced whispered voice (stage whisper) used necessarily on the stage, but also while repressive anger, indignation etc. Besides intimacy, secrecy or confidentiality (at times conveyed by the whispering itself more than by the topic), it betrays negative attitudes in general and it combines typically with breathy voice (e.g sexual intimacy (Poyatos182).

The voice can also be used to detect the sex, age, gender, and ethnic origins of an individual. According to Amrodriguez, ' 26 children, aged 4-14 read a standard passage, judges correctly guessed their sex $81 \%$ of the time. There was no anatomical basis, yet, for the difference in male and female voices. Boys appear to pronounce formant vowels at lower frequency than girls. Speech rate gets lower as people age(after 21 years old), the pitch goes up a little for older men... They had to guess from two photos, who the speaker was, they guessed $76.5 \%$ correctly; then they listened to voices and had to guess age, height, weight. People who had photos did no better than those in the voice only' (Amrodriguez 13, Web) '

\section{Pitch}

According to Reiman's concept of pitch, this is a vital part of the human voice; it is the rate of vibration of the vocal folds. Verbal languages use pitch to express emotional and other paralinguistic information etc. This is called intonation.

The sound of the voice changes as the rate of vibrations varies. As the number of vibrations per second increases, so does the pitch, meaning the voice would sound higher. Faster rates form higher voices, or higher pitches, while slower rates elicit deeper voices or lower pitches...the vibrations and the speed at which they vibrate, are dependent on the length and thickness of the vocal cords, as well as the tightening and relaxation of the muscles surrounding them. This explains why women generally have higher voices than men do; women tend to have higher voices because they have shorter vocal cords....pitch can also be affected by emotions, moods and inflections(Web).

The male vocal folds are from $17 \mathrm{~mm}$ and $25 \mathrm{~mm}$ in length, while the female is from $12.5 \mathrm{~mm}$ and $17.5 \mathrm{~mm}$ in length (Wikipedia Web). This difference goes to show that men and women have varied pitched voices. Pitch has been connected with sexual attractiveness. "A study done by researchers from Havard University, Florida State University and McMaster discovered that pitch predicted reproductive success of males amongst hunter gatherers. These researchers, studying the reproductive patterns of the 
Hadza, a tribe in Tanzania, found that men with lower pitched voices tended to have more children. These could be because the Hadza women chose men with lower pitched voices because they believed them to be better providers "(Reiman Web).

\section{Theoretical Framework}

The theoretical framework of this work is the theory of semiotics by Ferdinand de Saussure. Semiotics is the study of signs and sign processes, indications, designations, likeness, analogy, metaphor, symbolism, signification and communication (Wikipedia, Web). It studies the structure and meaning of language. It is divided into three branches: Semantics, Syntax and Pragmatics. According to Saussure language can be categorized as signs. He divided these signs into two: The Signifier and the Signified. The Signifier being the sound/gesture, while the Signified is the meaning or the image associated with such a sound/gesture.

For Saussure, the weight of the meaning is not on the Signifiers as they are arbitrary, as the signs can mean many things in different cultures but on the Signified.

\section{Analysis of Data from Purple Hibiscus}

1. 'Mba, there are no words in my mouth,' Jaja replied. What?!(Adichie, 2006. pg.21)----- What?! (Breathing Control)-signifies an ingressive exclamation, showing emotional questioning. The duration is fast.

2. 'Jaja!' Papa said. The shadow grew, enveloping the whites of Papa's eyes. (Adichie, 2006. pg.22)----'Jaja!' (Breathing Control) signifies an ingressive exclamation, indicating being panic-stricken. The duration is fast.

3. 'Kpa,' she said. ' 1 will not replace them.'(Adichie, 2006.pg. 23) -'Kpa' Laryngeal Control) Squawking, signifies a harsh voice, under strident and shrill voice qualities.

4. 'Sister Beatrice, what is it? Why have you done this? Are we not content with the anara we are offered in other sisters' homes? (Adichie, 2006.pg. 29) Falsetto voice, to express surprise and associated with affectionate ways of addressing people.

5. 'Brother Eugene!' Father Benedict said. His pale face broke into a smile when he saw papa. (Breathing Control) signifies an egressive exclamation, indicating surprise. The duration is fast.

6. 'When papa started the prayer, his voice quavered more than usual.' (Adichie, 2006.pg. 40) - (Laryngeal Control) Tremulous voice, to express when one is nervous or overwhelmed by emotion. 
7. 'Chinwe just wants to talk to you first', Ezinne whispered. (Adichie, 2006.pg. 58) - (Laryngeal Control) Whispery voice, (normal), to portray secrecy or confidentiality.

8. 'Eh? You like coming to this bush place?' His eyes widened theatrically. (Adichie, 2006.pg. 65) - 'Eh?' (Breathing Control) signifies an ingressive exclamation, showing emotional questioning. The duration is fast.

9. 'Gudu morni. Have you woken up, eh? Did you rise well?' (Adichie, 2006.pg. 66) - 'Eh?' (Breathing Control) signifies an ingressive exclamation, showing emotional questioning. The duration is fast.

10. Gudu morni. Did the people of your house rise well, oh? (Adichie, 2006.pg. 66) - 'Oh?' (Breathing Control) signifies an ingressive exclamation, showing emotional questioning. The duration is fast.

11. 'Omelora!' the man said in the forceful tone people used when they called others by their tittles. 'l am leaving now'. (Adichie, 2006. pg.68)----- Omelora! (Breathing Control)-signifies an ingressive and egressive exclamation, showing expectancy. The duration is fast.

12. 'Ogbunambala!' Papa said, 'Wait for me, 1 am praying with my family. 1 want to give you a little something for the children. You will also share my tea and bread with me' (Adichie, 2006. pg.68) -----. 'Ogbunambala!' (Breathing Control) 'signifies an egressive exclamation of surprise. The duration is fast.

13. 'Hei! Omelora! Thank sir. 1 have not drank milk this year' (Adichie, 2006. pg.68)----- 'Hei! Omelora' signifies a combination of ingressive and egressive exclamation. (Breathing Control) The duration is fast.

14. Neke! Neke! Neke! Kambili and Jaja have come to greet their old father!' (Adichie, 2006. pg.72)----- (Laryngeal Control) Squealing, signifies a short high cry expressing excitement, delight or strong emotion.

15. 'I hear that you came in yesterday,' he said. His lower lip quivered, as did his voice.' (Adichie, 2006. pg.72)-----Quivered (Laryngeal Control) Tremulous voice, to express when one is nervous or overwhelmed by emotion.

16. 'Ehye, 1 expect them tomorrow.' ' (Adichie, 2006. pg.73) ----- 'Ehye' (Breathing Control) signifies a combination of the ingressive and egressive exclamation, showing a repeated affirmation. The duration is fast.

17. 'Oh? Thank Eugene for me,' Papa Nnukwu said, smiling. (Adichie, 2006. pg.75) (Breathing Control) signifies an involuntary utterance of surprise. The duration is fast. 
18. 'Papa-Nnukwu does not look as healthy as last year,' I whispered close to Jaja's ear as we drove off. I did not want Kelvin to hear. (Adichie, 2006. pg.76) (Laryngeal Control.) Soft whispered voice signifies utmost secrecy.

19. Do you know that 1 am in your father's age group, gbo?' the old man asked. (Breathing Control) 'gbo' signifies an ingressive exclamation, showing emotional questioning. The duration is fast.

20. the idea that it was the family and not the man alone that married a wife, and later mama whispered, although we were alone in my room(Adichie, 2006. pg.81) (Laryngeal Control.) Normal whispered voice signifies secrecy.

Table 1

\section{Discussion of Findings}

Analysis of Data Using the Semiotic Theory.

\begin{tabular}{|c|c|c|}
\hline $\mathbf{S} / \mathbf{N}$ & SIGN AND SIGNIFIER & SIGNIFIED \\
\hline 1. & $\begin{array}{l}\text { 'Mba, there are no words in my } \\
\text { mouth,' Jaja replied. } \\
\text { What?! }\end{array}$ & $\begin{array}{l}\text { The underlined word signified an ingressive } \\
\text { sound under breathing control, showing } \\
\text { emotional questioning. }\end{array}$ \\
\hline 2. & $\begin{array}{l}\text { Jaja!' Papa said. The shadow } \\
\text { grew, enveloping the whites of } \\
\text { Papa's eyes. }\end{array}$ & $\begin{array}{l}\text { The underlined word signified an ingressive } \\
\text { sound under breathing control, indicating } \\
\text { being panic-stricken. }\end{array}$ \\
\hline 3. & $\begin{array}{l}\text { 'Kpa,' she said. '1 will not } \\
\text { replace them.' }\end{array}$ & $\begin{array}{l}\text { The underlined word Squawking, under } \\
\text { laryngeal control signified a harsh voice, } \\
\text { within strident and shrill voice qualities. }\end{array}$ \\
\hline 4. & $\begin{array}{l}\text { 'Sister Beatrice, what is it? } \\
\text { Why have you done this? Are } \\
\text { we not content with the anara } \\
\text { we are offered in other sisters' } \\
\text { homes? }\end{array}$ & $\begin{array}{l}\text { The words signified Falsetto voice, to } \\
\text { express surprise and associated with } \\
\text { affectionate ways of addressing people. }\end{array}$ \\
\hline 5. & 'Brother Eugene! & $\begin{array}{l}\text { The Underlined words signified egressive } \\
\text { sounds, under breathing control, indicating } \\
\text { surprise. }\end{array}$ \\
\hline 6. & $\begin{array}{l}\text { When papa started the prayer, } \\
\text { his voice quavered more than } \\
\text { usual.' }\end{array}$ & $\begin{array}{l}\text { The Underlined word signified tremulous } \\
\text { voice, under laryngeal control to express }\end{array}$ \\
\hline
\end{tabular}




\begin{tabular}{|l|l|l|}
\hline & & $\begin{array}{l}\text { when one is nervous or overwhelmed by } \\
\text { emotion. }\end{array}$ \\
\hline 7. & $\begin{array}{l}\text { 'Chinwe just wants to talk to } \\
\text { you first', Ezinne whispered. }\end{array}$ & $\begin{array}{l}\text { The Underlined word signified a whispery } \\
\text { voice, (normal), to portray secrecy or } \\
\text { confidentiality. }\end{array}$ \\
\hline 8. & $\begin{array}{l}\text { 'Eh? You like coming to this } \\
\text { bush place? }\end{array}$ & $\begin{array}{l}\text { The Underlined word signified an } \\
\text { ingressive sound, under breathing control } \\
\text { showing emotional questioning. }\end{array}$ \\
\hline 9. & $\begin{array}{l}\text { 'Gudu morni. Have you woken } \\
\text { up, eh? Did you rise well?' }\end{array}$ & $\begin{array}{l}\text { The underlined word signified an ingressive } \\
\text { sound, under breathing control showing } \\
\text { emotional questioning. }\end{array}$ \\
\hline 10. & $\begin{array}{l}\text { Gudu morni. Did the people of } \\
\text { your house rise well, oh? }\end{array}$ & $\begin{array}{l}\text { The Underlined word signified an } \\
\text { ingressive sound, under breathing control } \\
\text { showing emotional questioning. }\end{array}$ \\
\hline 11. & $\begin{array}{l}\text { 'Omelora!' the man said in the } \\
\text { forceful tone people used when } \\
\text { they called others by their } \\
\text { tittles. 'l am leaving now'. }\end{array}$ & $\begin{array}{l}\text { The underlined word signified an ingressive } \\
\text { and egressive sound, under breathing } \\
\text { control showing expectancy. }\end{array}$ \\
\hline 12. & $\begin{array}{l}\text { 'Ogbunambala!' Papa said, } \\
\text { 'Wait for me, l am praying with } \\
\text { my family. l want to give you a } \\
\text { little something for the } \\
\text { children. You will also share } \\
\text { my tea and bread with me' }\end{array}$ & $\begin{array}{l}\text { The Underlined word signified an egressive } \\
\text { sound, under breathing control showing } \\
\text { surprise. }\end{array}$ \\
\hline 13. & $\begin{array}{l}\text { 'Hei! Omelora! Thank sir. 1 } \\
\text { have not drank milk this year' }\end{array}$ & $\begin{array}{l}\text { The underlined words signified a } \\
\text { combination of egressive and ingressive } \\
\text { sounds, under (Breathing Control) It } \\
\text { signified gratitude. }\end{array}$ \\
\hline $\begin{array}{l}\text { Neke! Neke! Neke! Kambili } \\
\text { and Jaja have come to greet } \\
\text { their old father!' (Adichie, } \\
\text { 2006. pg.72)----() }\end{array}$ & $\begin{array}{l}\text { The underlined words signified Squealing, } \\
\text { under laryngeal control, is a short high cry } \\
\text { expressing excitement, delight or strong } \\
\text { emotion. }\end{array}$ \\
\hline
\end{tabular}




\begin{tabular}{|l|l|l|}
\hline 15. & $\begin{array}{l}\text { 'I hear that you came in } \\
\text { yesterday,' he said. His lower } \\
\text { lipquivered, as did his voice..' }\end{array}$ & $\begin{array}{l}\text { The underlined words tremulous voice, } \\
\text { under laryngeal control used to express } \\
\text { nervousness or when one is overwhelmed } \\
\text { by emotion. }\end{array}$ \\
\hline 16. & $\begin{array}{l}\text { 'Ehye, l expect them } \\
\text { tomorrow.' }\end{array}$ & $\begin{array}{l}\text { The underlined word signified a } \\
\text { combination of the ingressive and egressive } \\
\text { sounds, under breathing control showing a } \\
\text { repeated affirmation. }\end{array}$ \\
\hline 17. & $\begin{array}{l}\text { 'Oh? Thank Eugene for me,' } \\
\text { Papa Nnukwu said, smiling. }\end{array}$ & $\begin{array}{l}\text { The underlined word is an ingressive sound, } \\
\text { under breathing control that signified an } \\
\text { involuntary utterance of surprise. }\end{array}$ \\
\hline 18. & $\begin{array}{l}\text { 'Papa-Nnukwu does not look } \\
\text { as healthy as last year,' I } \\
\text { whispered close to Jaja's ear as } \\
\text { we drove off. I did not want } \\
\text { Kelvin to hear. }\end{array}$ & $\begin{array}{l}\text { The underlined gesture is done with a soft } \\
\text { whispered voice, under laryngeal control } \\
\text { and it signified utmost secrecy. }\end{array}$ \\
\hline 19. & $\begin{array}{l}\text { Do you know that l am in your } \\
\text { father's age group, gbo?' the } \\
\text { old man asked. }\end{array}$ & $\begin{array}{l}\text { The underlined word signified an ingressive } \\
\text { sound, under breathing control showing } \\
\text { emotional questioning. }\end{array}$ \\
\hline 20. & $\begin{array}{l}\text {..the idea that it was the } \\
\text { family and not the man alone } \\
\text { that married a wife, and later } \\
\text { mama whispered, although we } \\
\text { were alone in my room. }\end{array}$ & $\begin{array}{l}\text { The underlined word is a normal whispered } \\
\text { voice, under laryngeal control that signified } \\
\text { secrecy. }\end{array}$ \\
\hline
\end{tabular}

The analyses were hinged on the objectives of the study to enhance the consciousness of language users to the power of paralinguistic voice qualifiers during conversations.

The tables were classified into two sections: The Signifier (The sounds) and the Signified (The Meaning). There are 20 voice qualifiers identified from the above table.

Voice qualifiers can be used to show Emotional Questioning as in nos. 1-'what?' 8'Eh?', 9-'eh', 10-'Oh?', and 19-'gbo?'. Emotional questioning deepens the 
meanings of questions that are being asked, to indicate that the sender of the message demands an answer.

Nervousness: Nervousness and one being overwhelmed by emotion can be indicated through a quavering voice. This can be observed in nos. 6-, his voice quavered more than usual and 15- His lower lip quivered, as did his voice..'. Without this paralinguistic feature, there is no way to tell when one is nervous or overwhelmed by emotion.

Whispery Voice: This feature stops eavesdroppers from listening in on people's discussions, thereby enabling people to have private lives. This portrays a level of secrecy. In no. 7- Ezinne whispered. This is a normal whisper indicating secrecy. In no 18- 'I whispered close to Jaja's ear as we drove off. I did not want Kelvin to hear'. The gesture of mouth to ear whispering, portrays utmost secrecy. In no. 20- 'later mama whispered..' This is a normal whispered voice.

Qualifiers that showed Surprise: These sounds showed that the person expressed surprise. In no. 5-'Brother Eugene!. This is an indication of surprise. In no. 12'Ogbunambala!' is an expression of surprise. In no.8-oh? Is an expression of surprise.

Qualifiers that show affirmation: In no. 16- ${ }^{-E h y e}$ was used for repeated affirmation.

Qualifiers to indicate being panic-stricken. In no.2-The exclamation of the word 'Jaja!' portrayed panic at the character's behaviour.

Shrill/Strident Voices: In no. 3-'Kpa,' she said. ' 1 will not replace the them' The 'Kpa' is a harsh sound that the character used to affirm her resoluteness at not replacing the broken figurine, without the addition of that paralinguistic feature, the receiver of the message will not know the level of the resoluteness of the sender of the message, not to replace the broken figurine.

Falsetto voice: This is used to express surprise and associated with affectionate ways of addressing people. In no.4-

'Sister Beatrice, what is it? Why have you done this? Are we not content with the anara we are offered in other sisters' homes? This is an artificially or unusually high voice indicating the recipients were surprised but happy at her kind gesture.

Squeals: Qualifiers expressing delight: No 14- Neke! Neke! Neke! Kambili and Jaja have come to greet their old father!' This is an expression of delight, excitement or strong emotion. 
Qualifiers used to indicate expectancy: No.11-'Omelora!' the man said in the forceful tone people used when they called others by their tittles. ' 1 am leaving now'. This portrays expectancy.

Qualifiers used to indicate gratitude: No. 13-'Hei! Omelora! Thank sir. 1 have not drank milk this year'. This exclamation shows surprise and gratitude. This exclamation will go a long way to show to the sender of the message how grateful the receiver of the message is.

NOTE: The 'Oh?' in no. 10 and the 'Oh?' in no. 17 in the novel are not the same, though they were presented as such. The 'Oh?' in no. 10 indicates emotional questioning, while the 'Oh?' in no. 17 indicates surprise. It should have been 'Oh!' with an exclamation mark ('!') Not with a question mark ('?').

\begin{tabular}{|c|c|c|c|c|c|c|c|}
\hline $\mathbf{S} / \mathbf{N}$ & $\begin{array}{l}\text { Ingressive } \\
\text { Sound }\end{array}$ & $\begin{array}{l}\text { Egressive } \\
\text { Sound }\end{array}$ & $\begin{array}{l}\text { Squeaky } \\
\text { Voice }\end{array}$ & $\begin{array}{l}\text { Falsetto } \\
\text { Voice }\end{array}$ & $\begin{array}{l}\text { Tremulous } \\
\text { Voice }\end{array}$ & $\begin{array}{l}\text { Whispering } \\
\text { Voice }\end{array}$ & $\begin{array}{l}\text { Squealing } \\
\text { Voice }\end{array}$ \\
\hline 1. & $\sqrt{ }$ & & & & & & \\
\hline 2. & $\sqrt{ }$ & & & & & & \\
\hline 3. & & & $\sqrt{ }$ & & & & \\
\hline 4. & & & & $\sqrt{ }$ & & & \\
\hline 5. & & $\sqrt{ }$ & & & & & \\
\hline 6. & & & & & $\sqrt{ }$ & & \\
\hline 7. & & & & & & $\sqrt{ }$ & \\
\hline 8. & $\sqrt{ }$ & & & & & & \\
\hline 9. & $\sqrt{ }$ & & & & & & \\
\hline 10. & $\sqrt{ }$ & & & & & & \\
\hline 11. & $\sqrt{ }$ & & & & & & \\
\hline 12. & & $\sqrt{ }$ & & & & & \\
\hline 13 & $\sqrt{ }$ & $\sqrt{ }$ & & & & & \\
\hline 14. & & & & & & & $\sqrt{ }$ \\
\hline 15. & & & & & $\sqrt{ }$ & & \\
\hline 16. & $\sqrt{ }$ & $\sqrt{ }$ & & & & & \\
\hline 17. & $\sqrt{ }$ & & & & & & \\
\hline 18. & & & & & & $\sqrt{ }$ & \\
\hline 19. & $\sqrt{ }$ & & & & & & \\
\hline 20. & & & & & & $\sqrt{ }$ & \\
\hline
\end{tabular}

Table 2: Analysis of the Distribution of Sounds

In the table of distribution of sounds, it is observed that Ingressive sounds were the most used of all qualifiers; followed by egressive sounds, whispery voice and tremulous voice. The others were just used once. 


\section{Recommendations}

- Language users should learn to adopt the right use of voice qualifiers, to reduce ambiguity in discourse.

- Language teachers should teach their students how to master the use of voice qualifiers in discourse.

- Teaching voice qualifiers should be incorporated into the syllabus.

\section{Conclusion}

Voice qualifiers are the most understudied elements of human discourse. Humans can phonate on and off, and can equally raise or lower their pitches. By the sound of the voice we can differentiate when somebody is happy, threatened or frightened. Humans can consciously control their discourse by their voluntary laryngeal control. Purple Hibiscus is replete with voice qualifiers, which helped in creating clearer meanings in the text and showcased the decisive need of voice qualifiers in discourse.

\section{Works Cited}

Abercombie, David. Elements of General Phonetics. Edinburgh: Edinburgh University Press. 1967. Print.

Amrodriguez 13: Paralanguage. Quizzlet. 2014. Web.

Chimamanda, Adichie N. Purple Hibiscus. Lagos: Farafina, Kachifo Ltd. 2006.Print.

Davies, Alan \& Henry Widdowson. Reading and Writing. Techniques in Applied Linguistics ed. J. Allen \& S. Corder. 154-201. London: Oxford University Press, 1974. Print.

Gimson, A.C. An Introduction to the Pronunciation of English. London: Edward Arnold.2003. Print.

Hall, R.A. An Essay on Language. Philadelphia and New York: Chilton Books. 1968. Print.

O’Neil, Dennis. 'Hidden Aspects of Communication'. Tuesday, September 29, 2009. Web.

Poyatos, Fernando: Language and Communication: Paralinguistic Qualifiers: Our Many Voices. Vol.11, No. 3, pp. 181-195. Great Britain: Pergamon Press Plc. 1991. Print.

Reiman, Tonya. The Human Voice-Pitch. 2003-2006 
BodyLanguageUniversity.com.Web.

Weiss, Gilbert and Ruth Wodak. Critical Discourse Analysis: Theory and Interdisciplinarity New York: Palgrave/Macmillan, 2007.Web.

Wikipedia 25 January, 2014.17.30en.wikipedia.org/wiki/language.Web.

Wikipedia. The Human Voice 12 March 2014. 18:42.Web. 